\title{
SEGURANÇA DO PACIENTE COMO ESTRATÉGIA PARA PREVENÇÃO DE DANOS NA ASSISTÊNCIA DE ENFERMAGEM
}

Maria de Fátima Pereira da Silva, Hospital Regional de Cajazeiras (HRC), fmariap@yahoo.com.br

Maria do Carmo Andrade Duarte de Farias, Universidade Federal de Campina Grande Hospital Universitário Júlio Maria Bandeira de Mello (HUJB/(UFCG), carmofarias0@gmail.com

PALAVRAS-CHAVE: Segurança do paciente. Prática em saúde. Educação permanente.

\section{INTRODUÇÃO}

A segurança do paciente é uma temática transversal contemporânea que visa diminuir os riscos de danos causados pela assistência em saúde. O debate sobre a segurança do paciente vem crescendo no Brasil a partir da Portaria do Ministério da Saúde (MS) nº 529, de 01 de abril de 2013, que institui o Programa Nacional de Segurança do Paciente (PNSP), visando a qualificação do cuidado, bem como evitar que resultados indesejados aconteçam (BRASIL, 2013, p. 02). Nesta perspectiva, esta pesquisa teve por objetivo analisar o conhecimento da equipe de enfermagem sobre segurança do paciente.

\section{METODOLOGIA}

Trata-se de um estudo descritivo que foi realizado no Hospital Universitário Júlio Maria Bandeira de Mello (HUJB), na cidade de Cajazeiras - Paraíba. Teve a população composta por profissionais de enfermagem e desses 46 constituíram a amostra. A coleta de dados foi realizada entre 14 de fevereiro a 09 de março de 2017, utilizando-se de entrevista semiestruturada, após a emissão do parecer do Comitê de Ética em Pesquisa da Universidade Federal de Campina Grande. O corpus foi compilado pelo software Iramuteq (CAMARGO; JUSTO, 2013, p. 513). Realizada análise multivariada através da Classificação Hierárquica Descendente (CHD) que reteve 115 Unidades de Contexto Elementar (UCE) das 46 Unidades 
de Contexto Inicial (UCIs). As UCE's foram agrupadas em categorias a partir de testes do $x^{2}$ (qui-quadrado).

\section{DESCRIÇÕES, RESULTADOS, INTERPRETAÇÕES...}

Evidenciou-se através do software Iramuteq a divisão do corpus em quatro classes/categorias: Aspirações pelas práticas bem sucedidas; Condições para evitar erros; Construção de boas práticas; e Estruturação da cultura da segurança. Essas classes/categorias foram provenientes das respostas dos profissionais da enfermagem nas entrevistas.

A Classe/Categoria 1: Aspirações pelas práticas bem sucedidas - é composta por 21 UCEs, contempla o menor percentual no contexto temático, 18,3\%, em relação às demais classes. Compreende as palavras como núcleo de segurança, implantação, bom, expectativa, melhorar, muito, acontecer, esperar, hospital, conforto, querer e serviço, sendo compartilhada pela equipe de enfermagem.

A Classe/Categoria 2: Condições para evitar erros - teve a representação de 28 UCE's e correspondeu a $24,4 \%$ das palavras retidas. Os elementos mais frequentes representados nesta classe foram: paciente, inseguro, hora, medicação, puncionar, acesso, segurança, risco, orientar, dever, sempre, preciso e bem.

A Classe 3: Construção de boas práticas foi construída a partir de 31 UCE's e 27\% das palavras retidas, tendo como palavras mais frequentes: higienização das mãos, evitar, observar, norma, administração de medicamento, precisar, tudo, paciente, procedimento, corretamente, EPIs e identificação do paciente.

A Classe 4/Categoria: Estruturação da cultura da segurança foi formada a partir de 35 UCE's, correspondendo ao maior percentual no contexto temático $(30,3 \%)$ em relação às demais classes. As palavras mais frequentes foram: ação, processo, protocolo, instituição, educação permanente, qualidade da assistência, formação, Ministério da Saúde, promoção, saúde, importante, gestão e desenvolver.

As verbalizações elucidaram que as práticas são seguras se realizadas ancoradas no aprendizado durante a formação, em consonância com protocolos preestabelecidos pela instituição, ancorada através da educação permanente e tiveram sua eficácia comprovada cientificamente, corroborando com OLIVEIRA et al. (2014, p. 123). 


\section{PROPEX}

\section{CONSIDERAÇÕES FINAIS}

As quatro classes/categorias que emergiram do corpus: Aspirações pelas práticas bem sucedidas, Condições para evitar erros, Construção de boas práticas e Estruturação da cultura da segurança, refletiram estratégias dos profissionais da enfermagem do HUJB para a promoção da segurança do paciente. A construção de práticas bem sucedidas se dá ao longo da formação profissional e em constante relutar de práticas ancoradas no processo de educação permanente.

\section{REFERENNCIAS}

BRASIL. Ministério da Saúde. Portaria ${ }^{\circ} 529$, de $1^{\circ}$ de abril de 2013. Institui o Programa Nacional de Segurança do Paciente. Diário Oficial da União, Brasília, DF, 23 abr. $2013 f$.

CAMARGO, B. V.; JUSTO,A. M. Iramuteq: um software gratuito para análise de dados textuais. Temas em Psicologia, Florianópolis, SC, v. 21, n. 2, p. 513-18, 2013.

OLIVEIRA, R. M. et al. Estratégias para promover segurança do paciente: da identificação dos riscos às práticas baseadas em evidências. Esc Anna Nery,. Fortaleza, CE, v. 18, n. 1, p. 122-129, jan/mar, 2014. 